\title{
Bartsocas-Papas syndrome
}

INSERM

\section{Source}

INSERM. (1999). Orphanet: an online rare disease and orphan drug data base. BartsocasPapas syndrome. ORPHA:1234

Bartsocas-Papas syndrome is a rare, inherited, popliteal pterygium syndrome (see this term) characterized by severe popliteal webbing, microcephaly, a typical face with short palpebral fissures, ankyloblepharon, hypoplastic nose, filiform bands between the jaws and facial clefts, oligosyndactyly, genital abnormalities, and additional ectodermal anomalies (i.e. absent hair, eyebrows, lashes, nails). It is often fatal in the neonatal period, but patients living until childhood have been reported. 